\title{
Mesoporous silica nanoparticles trigger mitophagy in endothelial cells and perturb neuronal network activity in a size- and time-dependent manner
}

This article was published in the following Dove Press journal:

International Journal of Nanomedicine

8 May 2017

Number of times this article has been viewed

\section{Antonina Orlando' \\ Emanuela Cazzaniga' \\ Maria Tringali ${ }^{2}$ \\ Francesca Gullo 3 \\ Andrea Becchetti ${ }^{3}$ \\ Stefania Minniti ${ }^{1}$ \\ Francesca Taraballi4,5 \\ Ennio Tasciotti ${ }^{4,5}$ \\ Francesca $\operatorname{Re}^{1}$}

'Nanomedicine Center, School of Medicine and Surgery, University of Milano-Bicocca, Monza, ${ }^{2}$ Department of Environmental Sciences,

${ }^{3}$ Department of Biotechnologies and Biosciences, University of MilanoBicocca, Milan, Italy; ${ }^{4}$ Center for Biomimetic Medicine, Houston Methodist Research Institute (HMRI), ${ }^{5}$ Department of Orthopedics and Sports Medicine, Houston Methodist Hospital, Houston, TX, USA
Correspondence: Emanuela Cazzaniga Nanomedicine Center, School of Medicine and Surgery, University of Milano-Bicocca, 48 Via Cadore, Monza, MB 20900, Italy

Tel +3902 $6448821 \mathrm{I}$

Fax +390264488068

Email emanuela.cazzaniga@unimib.it
Purpose: Mesoporous silica nanoparticles (MSNPs) are excellent candidates for biomedical applications and drug delivery to different human body areas, the brain included. Although toxicity at cellular level has been investigated, we are still far from using MSNPs in the clinic, because the mechanisms involved in the cellular responses activated by MSNPs have not yet been elucidated.

Materials and methods: This study used an in vitro multiparametric approach to clarify relationships among size, dose, and time of exposure of MSNPs $(0.05-1 \mathrm{mg} / \mathrm{mL}$ dose range), and cellular responses by analyzing the morphology, viability, and functionality of human vascular endothelial cells and neurons.

Results: The results showed that 24 hours of exposure of endothelial cells to $250 \mathrm{~nm}$ MSNPs exerted higher toxicity in terms of mitochondrial activity and membrane integrity than $30 \mathrm{~nm}$ MSN at the same dose. This was due to induced cell autophagy (in particular mitophagy), probably consequent to MSNP cellular uptake ( $>20 \%)$. Interestingly, after 24 hours of treatment with $30 \mathrm{~nm}$ MSNPs, very low MSNP uptake $(<1 \%)$ and an increase in nitric oxide production $(30 \%, P<0.01)$ were measured. This suggests that MSNPs were able to affect endothelial functionality from outside the cells. These differences could be attributed to the different proteincorona composition of the MSNPs used, as suggested by sodium dodecyl sulfate polyacrylamidegel electrophoresis analysis of the plasma proteins covering the MSNP surface. Moreover, doses of MSNPs up to $0.25 \mathrm{mg} / \mathrm{mL}$ perturbed network activity by increasing excitability, as detected by multielectrode-array technology, without affecting neuronal cell viability.

Conclusion: These results suggest that MSNPs may be low-risk if prepared with a diameter $<30 \mathrm{~nm}$ and if they reach human tissues at doses $<0.25 \mathrm{mg} / \mathrm{mL}$. These important advances could help the rational design of NPs intended for biomedical uses, demonstrating that careful toxicity evaluation is necessary before using MSNPs in patients.

Keywords: mesoporous silica nanoparticles, nanotoxicity, endothelial cells, neurons, brain

\section{Introduction}

Mesoporous silica nanoparticles (MSNPs) are nanomaterials widely used as drug-delivery systems for biomedical applications, including diagnosis and tissue regeneration, due to their high hydrophilicity, large surface area, versatile chemistry, and good optical properties. ${ }^{1-3}$ MSNPs have been included by the Organisation for Economic Co-operation and Development (OECD) in the list of engineered nanomaterials relevant to environmental safety and human health.

However, concerns have been raised regarding potential human hazards of these NPs on a variety of cells and organs. Toxicity evaluation is imperative before allowing 
the development of clinical applications in the treatment and/or diagnosis of human diseases.

After intranasal instillation, MSNPs may interact with the vascular endothelium, and even in the absence of any specific functionalization, may reach the brain after crossing the blood-brain barrier, accumulating in neurons. ${ }^{4}$ The presence of MSNPs in specific tissues may not necessarily account for a consequent toxic effect. However, many cases of NP-related neurotoxicity have been reported, and neurological effects have been found in mice exposed to $\mathrm{SiO}_{2}{ }^{5}$ In vitro and in vivo studies on MSNPs have revealed that their toxic behavior varies with their size, shape, surface charge, type of coating material, and reactivity. ${ }^{6-8}$ For these reasons, careful toxicity testing is necessary before any NPs, MSNPs included, are declared to be safe for broad use.

To the best of our knowledge, few data are available in the literature about the underlying toxic-effect mechanisms of MSNPs on peripheral and brain vasculature ${ }^{6,9-12}$ or on neurons. ${ }^{13}$ No data are available on the potential effect of MSNPs on neuronal activity. To clarify these issues, this study aimed to investigate how the cellular biological response to MSNP exposure is affected by NP size, dose, and time of exposure. Cultured human umbilical vein endothelial cells (HUVECs) and immortalized human brain capillary ECs (HCMEC/D3 cell line) have been used as models of peripheral and central vasculature, respectively. The SKNSH human neuroblastoma cell line has been used as a model of cells with neuronal phenotypes, as evidenced by the high dopamine- $\beta$-hydroxylase activity, an enzyme found exclusively in nervous tissues. ${ }^{14}$ Alterations in cellular morphology, cell viability, nitric oxide (NO) production, autophagy, apoptosis, and neuronal activity have been investigated after cellular exposure to MSNPs. An additional issue, the so-called protein corona, generated by adsorption of proteins into the NP surface, must also be considered, because it may affect their toxicity profile.

\section{Materials and methods}

\section{Synthesis and characterization of MSNPs}

Materials for the synthesis of the SNPs were purchased from the following sources: tetraethyl orthosilicate, 3-(aminopropyl)triethoxysilane (APTES), hexadecyl trimethyl ammonium bromide (CTAB), fluorescein 5(6)-isothiocyanate, isopropyl alcohol (IPA), ethanol, $\mathrm{HCl}, 2$-mercaptoethanol, and $N$-(3diethylaminopropyl)- $N$ '-ethylcarbodiimide hydrochloride from Sigma-Aldrich (St Louis, MO, USA); and 2-ethylsulfonic acid, $\mathrm{NaCl}, \mathrm{NH}_{4} \mathrm{~F}$, and $\mathrm{N}$-hydroxysulfosuccinimide from Thermo Fisher Scientific (Waltham, MA, USA).
A modified Stöber reaction was used to synthesize MSNPs. ${ }^{15}$ In detail, $150 \mathrm{mg}$ ammonium fluoride and $134 \mathrm{mg}$ CTAB were dissolved in $45 \mathrm{~mL}$ water $\left(80^{\circ} \mathrm{C}\right.$ for 1 hour). Tetraethyl orthosilicate $(1 \mathrm{~mL})$ was then added dropwise to the solution, and the reaction proceeded for 2 hours at $80^{\circ} \mathrm{C}$. After two ethanol washes, MSNPs were left overnight in a $2 \% \mathrm{HCl}$-in-ethanol solution to remove surfactants. The NPs were washed with $50 \%$ ethanol and stored in IPA. MSNPs were modified with APTES in a solution of $2 \%$ APTES and $5 \%$ Millipore water by volume in IPA at a concentration of $1 \mathrm{mg}$ NPs/mL APTES solution.

Dynamic light scattering (DLS) and $\zeta$-potential characterization were performed using a Zetasizer Zen 3600 (Malvern Instruments, Malvern, UK). For DLS, scattered light detection was measured at $90^{\circ}$ to the incident beam (a $25 \mathrm{~mW}$ laser at $660 \mathrm{~nm}$ wavelength). For $\zeta$-potential analysis, the same parameters were used, but scattered light was detected at $150^{\circ}$.

The morphology of the MSNPs was observed by transmission electron microscopy (TEM) and scanning electron microscopy (SEM). SEM images were acquired under high vacuum, at $20 \mathrm{kV}$, spot size 3-5, using an FEI Quanta 400 FEG ESEM equipped with an Everhart-Thornley secondary electron detector. Samples were prepared by introducing one drop (about $2 \mu \mathrm{L}$ ) of aqueous suspension $(0.1 \mathrm{mg} / \mathrm{mL})$ of the particles on an SEM stub (Ted Pella Inc, Redding, CA, USA) and allowing the solvent to dry in air. Samples were sputter-coated with a $10 \mathrm{~nm}$ layer of gold using a Plasma Sciences CrC-150 sputtering system (Torr International Inc, New Windsor, NY, USA) before analysis. For TEM analysis, samples were prepared by drying NPs onto 300-mesh carbon-coated copper grids. Samples were then sent to the University of Texas in Austin for imaging by Dr Tony Hu.

\section{Cell cultures}

HUVECs (commercially purchased from Lonza, Walkersville, $\mathrm{MD}$ ) and HCMEC/D3 cells (provided by Institut National de la Santé et del la Recherche Médicale [INSERM], Paris, France) were grown as previously described. ${ }^{16,17}$ SKNSH human neuroblastoma cells (commercially purchased from American Type Culture Collection, Manassas, VA, USA) were maintained in Dulbecco's Modified Eagle's Medium supplemented with $10 \%$ heat-inactivated fetal bovine serum, penicillin $(100 \mathrm{U} / \mathrm{mL})$, streptomycin $(100 \mu \mathrm{g} / \mathrm{mL})$, and L-glutamine $(2 \mathrm{mM})$ in a $5 \% \mathrm{CO}_{2}$ humidified incubator at $37^{\circ} \mathrm{C}$. The cells were differentiated with $10 \mu \mathrm{M}$ retinoic acid for 5 days. ${ }^{18}$ 


\section{Treatment of cells with MSNPs}

The MSNP solution of $0.1 \mathrm{mg} / \mathrm{mL}$ in isopropanol, which sterilized the NPs, was probe-sonicated (Vibra-Cell ${ }^{\mathrm{TM}}$ ultrasonic liquid processor; Sonics and Materials Inc, Newtown, CT, USA) for 10 minutes at $70 \%$ power, then centrifuged at $14,000 \times g$ for 5 minutes. The supernatant was removed and replaced with cell media. The MSNPs were probe-sonicated again for 10 minutes at $50 \%$ power and used to treat the cells. HUVECs at $80 \%-90 \%$ confluence or HCMEC/D3 cells were treated for 2 and 24 hours with different MSNP doses: $0.05-1 \mathrm{mg} / \mathrm{mL}$. After treatment, mitochondrial activity, membrane integrity, and endothelial functionality were investigated. SKNSH cells were treated only at the NP concentrations with the least toxicity on HUVECs $(<0.25 \mathrm{mg} / \mathrm{mL})$ for 2 and 24 hours. After treatment, mitochondrial activity and membrane integrity were tested.

\section{Assessment of mitochondrial enzymatic activity by MTT assay}

After cell treatment with MSNPs, $0.5 \mu \mathrm{g} / \mathrm{mL}$ of MTT solution was added to the cells for 2 hours. After incubation, ethanol was added to each well to dissolve the formed formazan crystals, and absorbance at $550 \mathrm{~nm}$ was measured with a microplate reader (Victor $^{3} 1420$ multilabel counter; PerkinElmer, Waltham, MA, USA). Untreated cells were used as a negative control. Particles alone were used to check possible interference with the photometric method. Each sample was analyzed at least in triplicate. ${ }^{16,19}$

\section{Assessment of membrane integrity by lactate dehydrogenase (LDH) leakage}

After cell treatment with MSNPs, the release of the cytoplasmic enzyme LDH into the surrounding medium was analyzed using the cytotoxicity-detection kit according to the manufacturer's instructions (Hoffman-La Roche Ltd, Basel, Switzerland). Optical density was measured with a microplate reader $\left(\right.$ Victor $\left.^{3}\right)$ at $490 \mathrm{~nm}$. The relative amount of released LDH was normalized to the total amount of LDH of control cells (untreated cells), which were completely lysed with lysis buffer provided in the kit. Particles alone were used to check possible interference with the photometric method. Each sample was analyzed at least in triplicate.

\section{Assessment of endothelial functionality by $\mathrm{NO}$ production}

NO production was measured in conditioned media of cells using the Griess method. ${ }^{16,20}$ The absorbance of each sample was measured at $540 \mathrm{~nm}$ using a microplate reader $\left(\right.$ Victor $\left.^{3}\right)$.
Particles alone were used to check possible interference with the photometric method.

\section{Evaluation of cellular autophagy and apoptosis by sodium dodecyl sulfate polyacrylamide-gel electrophoresis (SDS-PAGE)/Western blotting (WB)}

Expression level of LC3 II, a common indicator of autophagy, and activation of caspase 3, an indicator of apoptosis, were investigated by SDS-PAGE, followed by immunoblotting analysis. ${ }^{21}$ Briefly, total cellular lysates were obtained and the cells resuspended in lysis buffer (containing a $2 \%$ SDS, $50 \mathrm{mM}$ Tris-HCl, pH 6.8, 1 mM complete protease-inhibitor cocktail; Hoffman-La Roche) and phosphatase inhibitors ( $2 \mathrm{mM} \mathrm{Na}$ orthovanadate, $1 \mathrm{mM} \mathrm{Na}$ fluoride, $1 \mathrm{mM} \mathrm{Na}$ pyrophosphate). An aliquot of the total cellular lysates was analyzed for protein content by bicinchoninic acid assay (Sigma-Aldrich). After being boiled for 5 minutes at $100^{\circ} \mathrm{C}$, an aliquot of each sample containing $15 \mu \mathrm{g}$ total proteins was subjected to SDS-PAGE using precast NuPAGE $4 \%-12 \%$ gel (Thermo Fisher Scientific). Protein bands were transferred to a nitrocellulose membrane by WB and analyzed by immunoblotting. To detect $\beta$-actin and caspase 3 , the membrane was blocked for 30 minutes at $37^{\circ} \mathrm{C}$ in Tris-buffered saline containing $0.1 \%$ Tween and $5 \%$ nonfat milk and incubated overnight at $4{ }^{\circ} \mathrm{C}$ with anti- $\beta$-actin (1:1,500; Sigma-Aldrich) or anti-caspase 3 (1:1,000; Cell Signaling Technology, Beverly, MA, USA). For LC3 II, the membrane was blocked for 30 minutes at $37^{\circ} \mathrm{C}$ in Tris-buffered saline containing $0.1 \%$ Tween and $5 \%$ bovine serum albumin and incubated overnight at $4{ }^{\circ} \mathrm{C}$ with anti-LC3 antibody $(1: 1,000$; Cell Signaling Technology). Immunoreactive proteins were revealed by enhanced chemiluminescence after incubation for 2 hours at room temperature with horseradish peroxidase-conjugated secondary antibodies (Thermo Fisher Scientific). The intensity of chemiluminescent spots was semiquantitatively estimated with an ImageQuant LAS4000 (GE Healthcare, Little Chalfont, UK) and expressed as the ratio between the intensity of the spot of interest and the intensity of $\beta$-actin bands for cell lysates. ${ }^{16}$

\section{Measurement of MSNP uptake by inductively coupled plasma-optical emission spectrophotometry (ICP-OES) analysis}

Cellular uptake of MSNPs $(0.25 \mathrm{mg} / \mathrm{mL})$ by HUVECs was measured after 2 hours of incubation at $37^{\circ} \mathrm{C}$. After 
incubation, a gentle wash of the cells with $0.1 \%$ trypsin for 3 minutes was done to remove the particles adherent to the cells. ${ }^{17}$ After this, cells were detached from the plate with trypsin for 15 minutes. Cell pellets were suspended in $1 \mathrm{~mL}$ phosphate-buffered saline and digested by adding $4 \mathrm{~mL}$ of aqua regia $\left(\mathrm{HNO}_{3} 65 \%\right.$ and $\mathrm{HCl} \mathrm{37 \%}$; Sigma-Aldrich). After 72 hours, the digested samples were diluted with 10 $\mathrm{mL}$ distilled water. The amount of silica internalized by the cells was determined by using ICP-OES (Optima 7000 DV; PerkinElmer). A certified standard reference material of $\mathrm{Si}$ $1,000 \mathrm{mg} / \mathrm{L}$ (PerkinElmer Pure) was used for calibration and quality control. The operating parameters of ICP-OES used an emission line at $251.611 \mathrm{~nm}$ in axial view, and sample solutions were measured in triplicate. The limit detection of the instrument is $0.01 \mathrm{mg} / \mathrm{L}$.

\section{Evaluation of neuronal activity by multielectrode-array (MEA) technology}

CD1 neonatal mice were purchased from Envigo (Huntingdon, UK). Experiments were carried out according to the Principles of Laboratory Animal Care (directive 86/609/ EEC), endorsed by the ethical committee of the University of Milano-Bicocca. All efforts were made to minimize the number of animals used. Primary cultures of cortical neurons were prepared as previously described. ${ }^{22,23}$ Briefly, all of the cerebral cortex (excluding the hippocampus) was removed from decapitated postnatal mice $(\mathrm{P} 1-\mathrm{P} 3)$, cut into $1 \times 1 \times 1$ $\mathrm{mm}$ pieces, and digested by trypsin $(0.15 \%)$ and DNase $(10 \mu \mathrm{g} / \mathrm{mL})$ at $37^{\circ} \mathrm{C}$ for 20 minutes. After enzyme digestion, cells were mechanically dissociated by means of trituration and plated at densities of $\sim 900 \times 10^{3}$ cells $/ \mathrm{mL}$ on MEA petri dishes precoated with polyethyleneimine $0.1 \%$ (wt/vol) and laminin $20 \mu \mathrm{g} / \mathrm{mL}$ (30 $\mu \mathrm{m}$ diameter indium tin oxide electrodes spaced $200 \mu \mathrm{m}$ apart; MultiChannel Systems, Reutlingen, Germany). Each dish had a recording area of $\sim 2 \times 2 \mathrm{~mm}$, where on average $\sim 7,000$ cells were present. After 3 hours of incubation, the plating medium was replaced by neurobasal medium supplemented with B27 (Thermo Fisher Scientific), glutamine $1 \mathrm{mM}$, and basic fibroblast growth factor $10 \mathrm{ng} / \mathrm{mL}$, and the culture was maintained at $37^{\circ} \mathrm{C}$ in $5 \% \mathrm{CO}_{2}$. Half of the medium volume was refreshed every 3 days, and the day before experiments. The cultures in MEA dishes were covered with gas-permeable covers (MEAMEM; ALA Scientific Instruments, Farmingdale, NY, USA) throughout the culture period ( $\sim 22$ days in vitro).

\section{MEA electrophysiology}

Primary cultures of ex vivo cortical neuronal networks showed spontaneous electrophysiological activity without receiving external stimulation. Such in vitro activity can be recorded by MEA technology in a noninvasive way, with good temporal and spatial resolution, as described previously. 22,24,25 Briefly, raw analogue signals were sampled at $40 \mathrm{kHz}$ using MEA-1060-INV preamplifiers (bandwidth 0.1-8 kHz; MultiChannel Systems) and an MEA Workstation (bandwidth 0.1-8 kHz; Plexon, Dallas, TX, USA). Offline Sorter software (Plexon) was used to clean data appropriately from artifacts and assign spikes into multiunit (1-4) electrodes by using principal-component analysis-based software. During this process, we applied the following procedures: 1) removal of spike using the Mahalanobis threshold (range 1.8-1.4), with $P$-value of multivariate analysis of variance (ANOVA) sorting quality statistics $<0.01$ among the identified units; and 2) when the previous procedure led to excessive spike invalidation, we manually removed the spikes invading the adjacent-unit ellipsoids (the latter method was very effective in decreasing $P$-values, with only a limited number of erased spikes). On the basis of an unsupervised learning approach consisting of data-reducing principal-component analysis based on the Fano factor (FF) as a feature and followed by $k$-means clustering, ${ }^{25,26}$ we statistically identified two neuronal clusters: inhibitory (i, black) and excitatory (e, red) neurons. Cluster processing was enriched by means of an outlier-removal procedure that discarded the units whose Mahalanobis distances from the centroid of the cluster were greater than the fixed threshold at 1.4. To analyze the burst structure, we applied a running window of variable duration (10 milliseconds to 1 second), ${ }^{27}$ in order to detect burst duration (BD). Moreover, we identified the number of spikes engaged in each burst (SN), the spike rate (SR), and the interburst interval (IBI). For all of the experiments, we noticed that the two neuronal clusters obeyed the following rules in control conditions: $\mathrm{BD}_{\mathrm{e}}<\mathrm{BD}_{\mathrm{i}}, \mathrm{SN}_{\mathrm{e}}<\mathrm{SN}_{\mathrm{i}}$, $\mathrm{SR}_{\mathrm{e}}<\mathrm{SR}_{\mathrm{i}}, \mathrm{FF}_{\mathrm{e}}<\mathrm{FF}_{\mathrm{i}}$, and $\mathrm{IBI}_{\mathrm{e}} \leq \mathrm{IBI}_{\mathrm{i}}$. For each parameter, data were computed in half-hour time segments and identified as time points in the experiment's plots corresponding to the control and treatment time course. ${ }^{22,24,25,28}$

\section{Analysis of MSNP protein coronas by SDS-PAGE}

MSNPs $(0.25 \mathrm{mg} / \mathrm{mL})$ of each size were incubated under constant movement with $1 \mathrm{~mL}$ of completed cell-culture medium with $5 \%$ or $10 \%$ of serum at $37^{\circ} \mathrm{C}$ for 24 hours. After incubation, samples were centrifuged at $1,000 \times g$ for 20 minutes at room temperature to remove unbound proteins from NP surfaces. Pellets obtained were washed three times with $1 \mathrm{~mL}$ of phosphate-buffered saline and centrifuged as described earlier. After the last step of 
washing, pellets were resuspended in $30 \mu \mathrm{L}$ of water and analyzed by SDS-PAGE on a $12 \%$ bis-Tris-glycine gel (Thermo Fisher Scientific), followed by EZ blue staining. As controls, an aliquot of medium without MSNPs before and after centrifugation were used. The intensity of protein bands was determined by ImageJ software.

\section{Statistical analysis}

All experiments were carried out at least in triplicate. Statistical analyses were performed using OriginPro 8 (OriginLab, Northampton, MA, USA). Data were compared using Student's unpaired $t$-test and expressed as mean \pm standard error of mean. Data from MEA electrophysiology were analyzed using OriginPro 7.0 software (OriginLab); the results are expressed as mean \pm standard error of mean values, with $\mathrm{n}$ indicating the number of experiments performed. Statistical significance was evaluated using ANOVA followed by Bonferroni test, with $P<0.05$.

\section{Results}

\section{Characterization of NPs}

DLS results $(1,059 \pm 178.8 \mathrm{~nm}$, polydispersity index 0.383 for $250 \mathrm{~nm}$ MSNPs; $932 \pm 159.3 \mathrm{~nm}$; polydispersity index 0.274 for $30 \mathrm{~nm}$ MSNPs) demonstrated a clear tendency of both types of MSNPs to form small aggregates. The $\zeta$-potential of NPs was negative, with values of $-10.5 \mathrm{mV}$ and $-13.1 \mathrm{mV}$ for 30 and $250 \mathrm{~nm}$ MSNPs, respectively. SEM (Figure 1A and C) and TEM (Figure 1B and D) images indicated that MSNPs displayed uniform size (37.5-62.2 nm for $30 \mathrm{~nm}$ MSNPs, 253-281 nm for $250 \mathrm{~nm}$ MSNPs) and spherical shape.

\section{Effect of MSNP treatment on mitochondrial enzymatic activity}

Cells were treated with 30 or $250 \mathrm{~nm}$ size MSNPs at different doses, and mitochondrial enzymatic activity, an indicator of cell viability, was assessed by MTT assay. The results showed that the treatment of HUVECs with $250 \mathrm{~nm}$ MSNPs induced mitochondrial dysfunction at 2 hours, starting at an NP concentration of $0.25 \mathrm{mg} / \mathrm{mL}$. When the NP dose was increased, no decrease in mitochondrial activity was detected. On the contrary, when the incubation of cells with NP was prolonged to 24 hours, mitochondrial dysfunction was dose-dependent, dropping to $10 \%$ of residual mitochondrial activity (Figure 2A). MSNPs of $30 \mathrm{~nm}$ caused an alteration in mitochondrial function only after 2 hours of treatment with $\mathrm{NP}$ at doses $>0.5 \mathrm{mg} / \mathrm{mL}$. With increased cell-exposure time (24 hours) and NP dose (up to $1 \mathrm{mg} / \mathrm{mL}$ ), 30\% of residual mitochondrial activity was registered (Figure $2 \mathrm{~B}$ ).
A

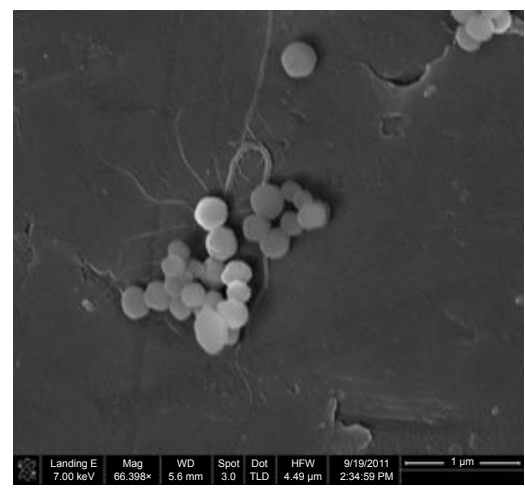

C

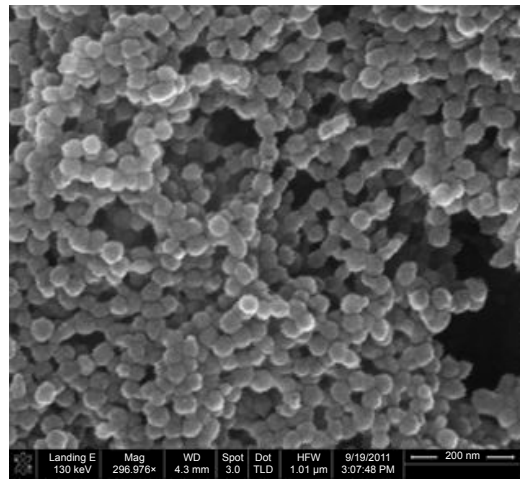

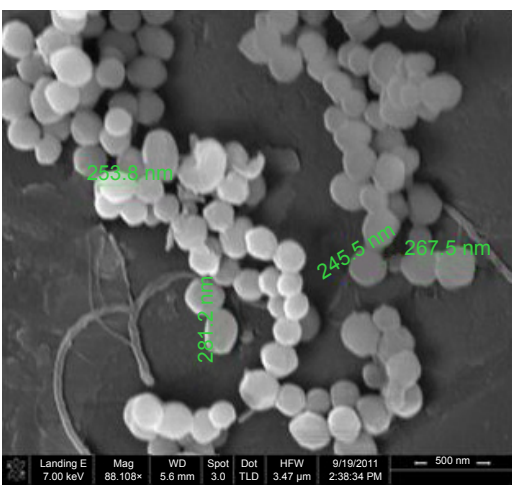
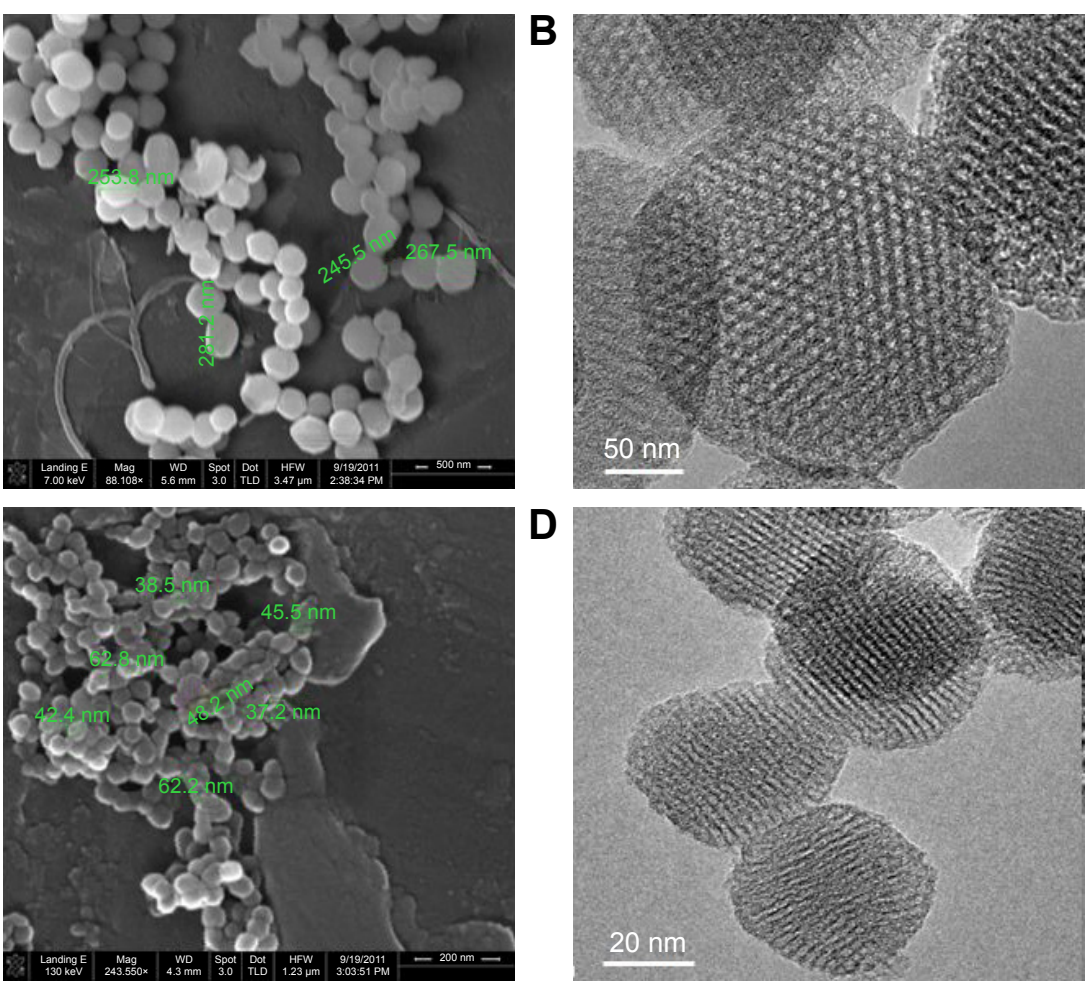

D

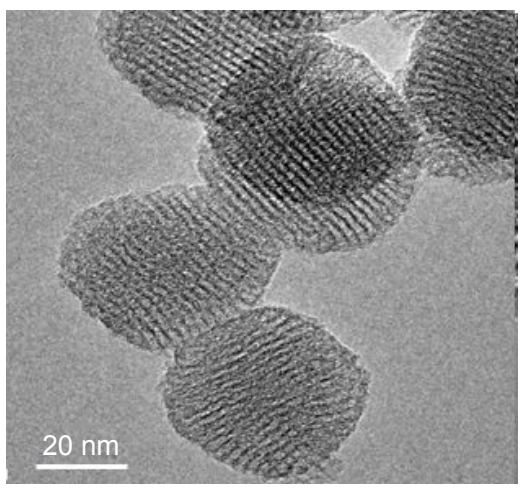

Figure I Characterization of MSNPs by SEM and TEM.

Notes: MSNPs of different sizes were synthesized using a modified Stöber reaction. The morphology of the MSNPs was observed by SEM (A, C) and TEM (B, D). The results showed that the two preparations of MSNPs displayed uniform size: $253-28 \mathrm{~nm}$ for $250 \mathrm{~nm}$ MSNPs (A, B) and 37.5-62.2 nm for 30 nm MSNPs (C, D), and were spherical.

Abbreviations: MSNPs, mesoporous silica nanoparticles; SEM, scanning electron microscopy; TEM, transmission electron microscopy. 
Treatment of HCMEC/D3 cells with $250 \mathrm{~nm}$ MSNPs did not affect mitochondrial function at any NP concentrations or times tested (Figure 2C), whereas treatment with $30 \mathrm{~nm}$ MSNPs resulted in a slight decrease in mitochondrial activity only after 24 hours of treatment (Figure 2D). Mitochondrial function of SKNSH cells was not affected by MSNP treatment (Figure 2E and F).

\section{Effect of MSNP treatment on membrane integrity}

Cells were treated with 30 or $250 \mathrm{~nm}$ MSNPs at different doses, and membrane integrity was assessed by measuring LDH release. The results showed that the treatment of
HUVECs with $250 \mathrm{~nm}$ MSNPs resulted in a strong increase in LDH release after 24 hours of incubation with all NP doses tested (Figure 3A). MSNPs of $30 \mathrm{~nm}$ induced a slight increase in LDH release by HUVECs only at the highest NP dose tested after 24 hours of incubation (Figure 3B). In contrast to HUVECs, the membrane integrity of HCMEC/D3 and SKNSH cells was not significantly affected by MSNP treatments (Figure 3C-F).

\section{Effect of MSNP treatment on endothelial functionality}

Cells were treated with 30 or $250 \mathrm{~nm}$ MSNPs at different doses, and endothelial functionality was assessed by
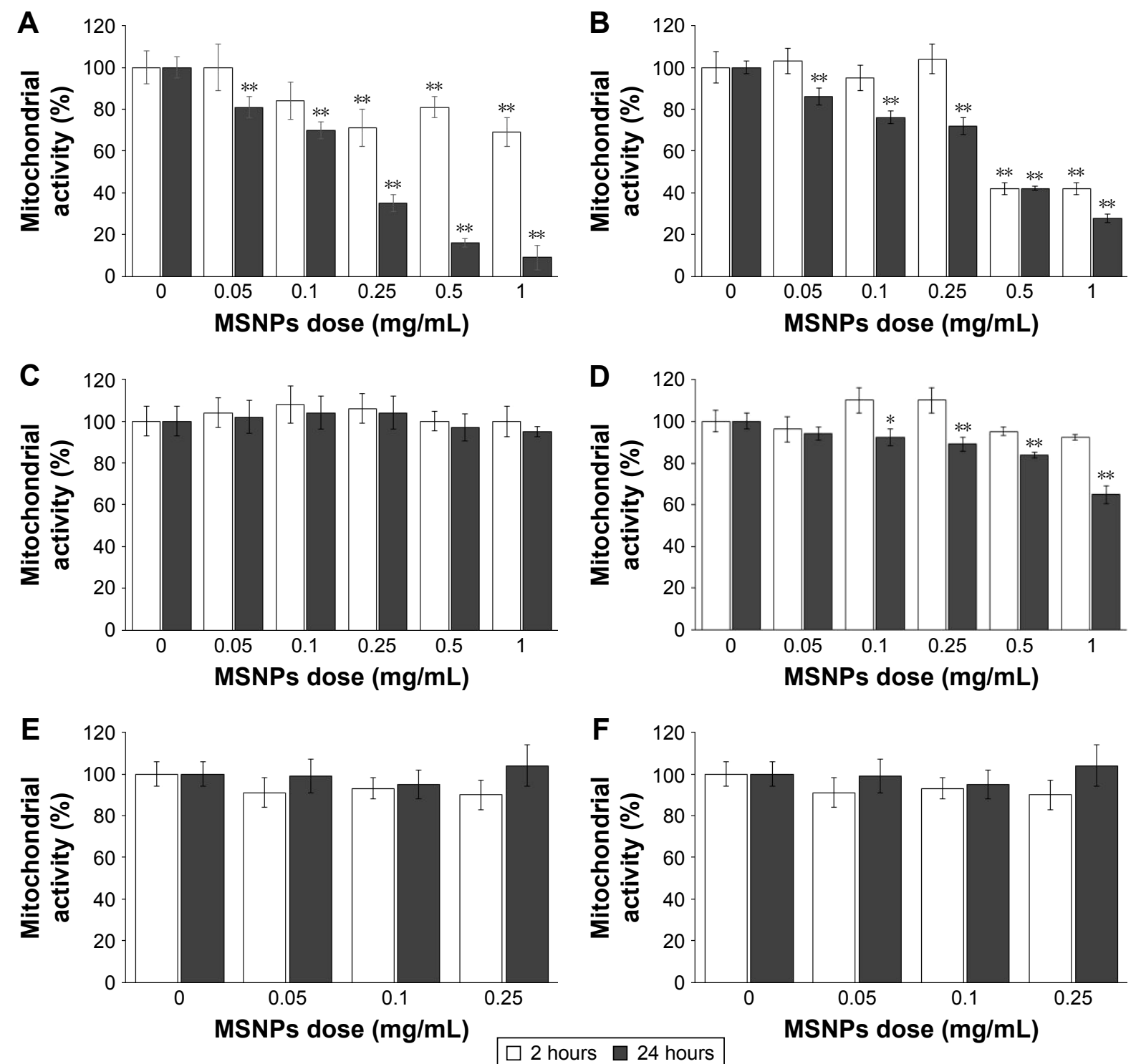

Figure 2 Effect of MSNP treatment on mitochondrial activity assessed by MTT assay.

Notes: HUVECs (A, B) and HCMEC (C, D) and SKNSH cell lines (E, F) were incubated with different concentrations, ranging from 0.05 to I mg/mL of MSNPs of $250 \mathrm{~nm}$ (A, C, E) or $30 \mathrm{~nm}$ (B, D, F) for 2 and 24 hours. Mitochondrial activity was evaluated by MTT. Results reported as percentages, using untreated cells as a control. Data reported as mean \pm standard error of mean of triplicate experiments. Results were compared by Student's $t$-test. $* P<0.05 ; * * P<0.01 ; 0$ dose of MSNPs indicates untreated cells. Abbreviations: MSNP, mesoporous silica nanoparticle; HUVECs, human umbilical vein endothelial cells. 

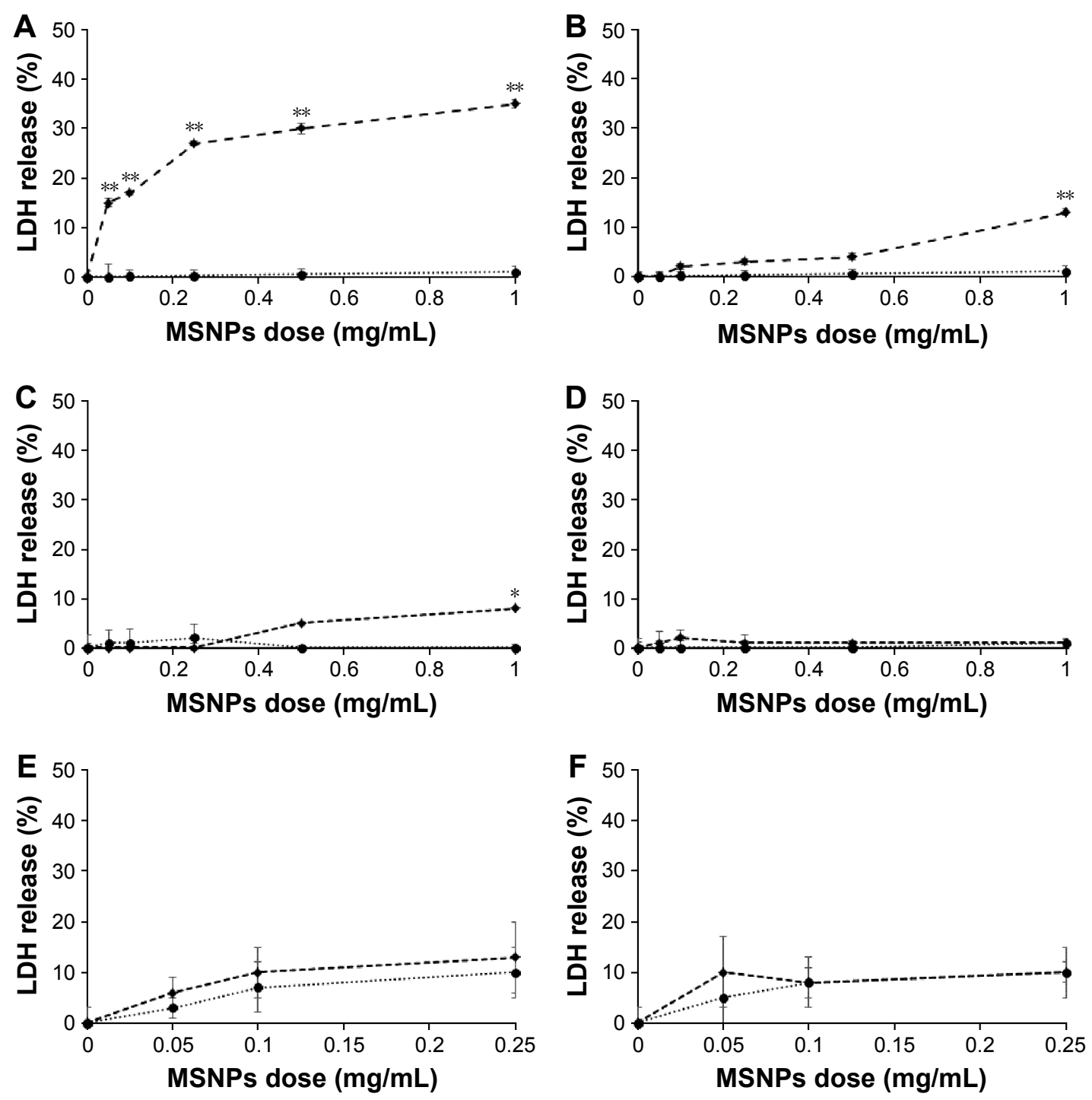

$$
\cdots \cdot \cdots 2 \text { hours } \quad-\cdots \cdots 24 \text { hours }
$$

Figure 3 Effect of MSNP treatment on membrane integrity assessed by LDH-release assay.

Notes: HUVECs (A, B) and HCMEC (C, D) and SKNSH cell lines (E, F) were incubated with different concentrations, ranging from 0.05 to I mg/mL of MSNP of $250 \mathrm{~nm}$ $(\mathbf{A}, \mathbf{C}, \mathbf{E})$ or $30 \mathrm{~nm}(\mathbf{B}, \mathbf{D}, \mathbf{F})$ for 2 and 24 hours. LDH release was evaluated by LDH assay. Results are reported as percentages using untreated cells as a control. Data reported as mean \pm standard error of triplicate experiments. Results were compared by Student's $t$-test. $* P<0.05 ; * * P<0.01 ; 0$ dose of MSNPs indicates untreated cells.

Abbreviations: MSNP, mesoporous silica nanoparticle; HUVECs, human umbilical vein endothelial cells; LDH, lactate dehydrogenase.

measuring the production of NO by the Griess method. Treatment of HUVECs with $250 \mathrm{~nm}$ MSNPs did not affect NO production (Figure 4A). On the contrary, treatment with $30 \mathrm{~nm}$ MSNPs at a concentration of $1 \mathrm{mg} / \mathrm{mL}$ induced a marginal increase of NO production after 2 hours of incubation (Figure 4B). This can hardly be regarded as a toxic effect, since it occurred at very high particle exposure and no dose response was apparent.

\section{Effect of MSNP treatment on cellular autophagy and apoptosis}

In order to understand if treatment with MSNPs triggered cell survival or death, activation of the autophagy and/or apoptosis pathway was investigated by measuring the activation of LC3 II and caspase 3, respectively. Treatment with either $250 \mathrm{~nm}$ (Figure 5A and C) or $30 \mathrm{~nm}$ (Figure 5B and D) MSNPs induced an increase in LC3 II by HUVECs, starting from an NP dose of $0.1 \mathrm{mg} / \mathrm{mL}$. Activation of autophagy by $250 \mathrm{~nm}$ MSNPs seems to occur earlier compared to $30 \mathrm{~nm}$ particles. No significant increase in caspase 3 levels was detected after MSNP treatments (data not shown).

\section{Evaluation of MSNP cellular uptake}

The quantity of MSNPs internalized by HUVECs was measured by ICP-OES after 2 hours of treatment with $0.25 \mathrm{mg} / \mathrm{mL}$ NPs, the concentration previously shown to have low toxicity 

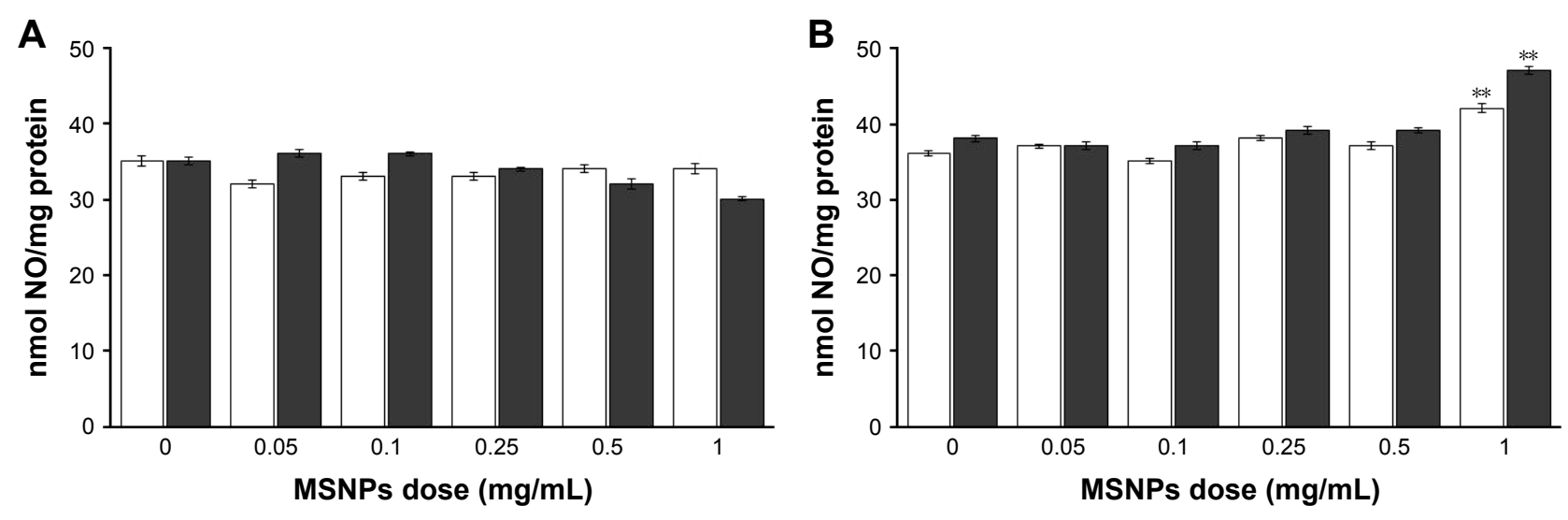

$\square 2$ hours $\square 24$ hours

Figure 4 Effect of MSNPs on endothelial dysfunction assessed by measuring NO production.

Notes: HUVECs were incubated with different concentrations, ranging from 0.05 to I mg/mL MSNPs of $250 \mathrm{~nm}$ (A) or $30 \mathrm{~nm}$ (B) for 2 or 24 hours. NO production was measured in conditioned media by Griess method. Data are mean \pm standard error of three separate experiments performed in triplicate. Results were compared by Student's $t$-test. $* * P<0.01 ; 0$ dose of MSNPs indicates untreated cells.

Abbreviations: MSNPs, mesoporous silica nanoparticles; HUVECs, human umbilical vein endothelial cells.

A
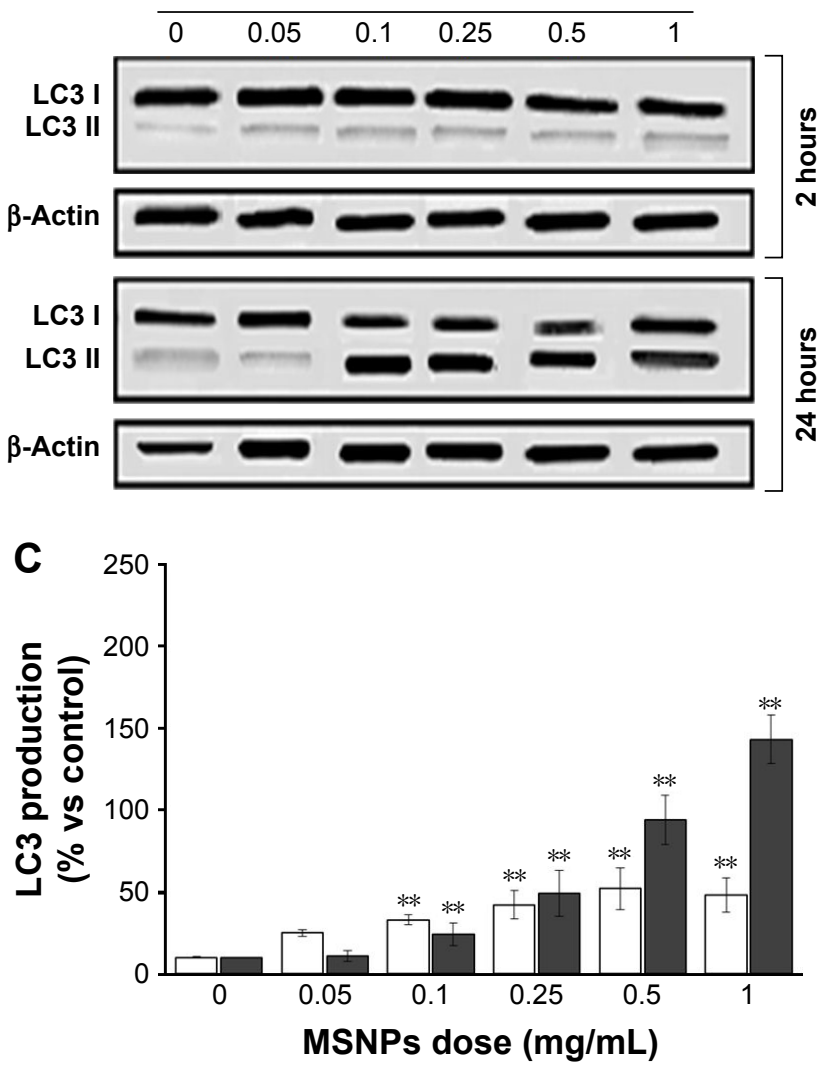

B
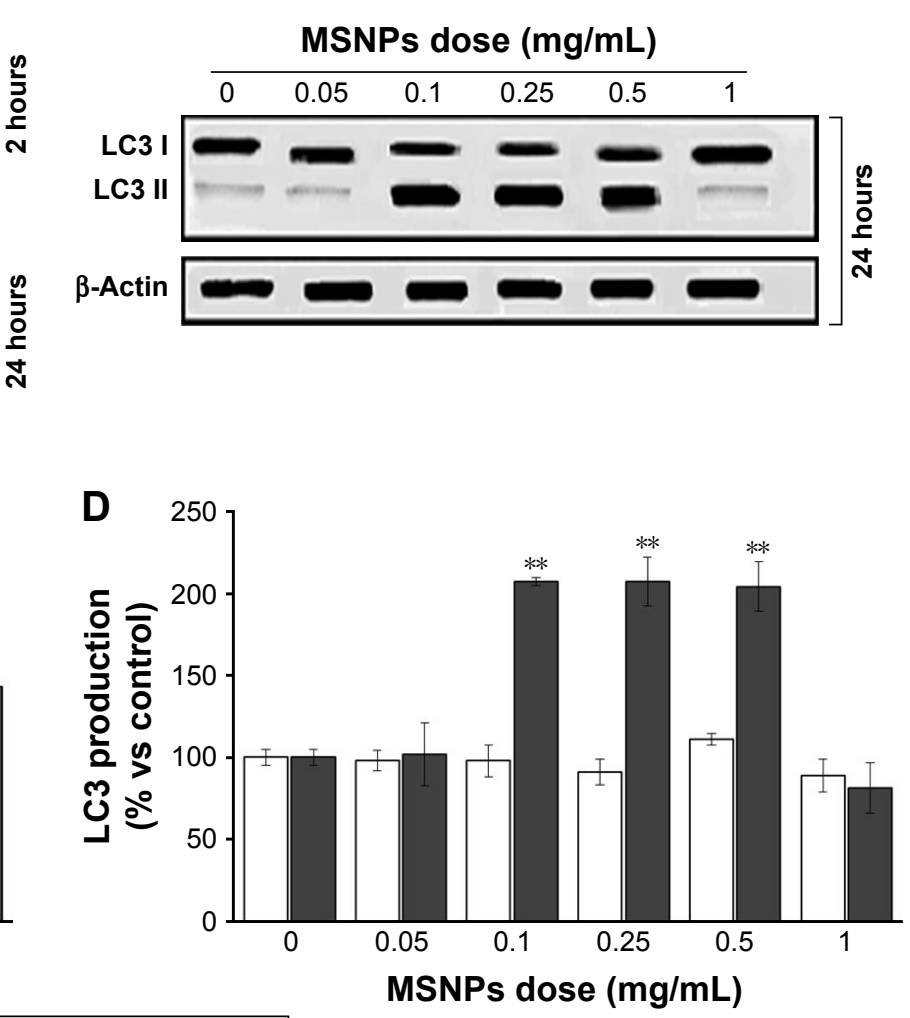

Figure 5 Effect of MSNPs on cell autophagy assessed by measuring the production of LC3 mediator.

Notes: HUVECs were incubated with different concentrations $(0.05-1 \mathrm{mg} / \mathrm{mL})$ of MSNPs of $250 \mathrm{~nm}$ (A, C) or of 30 (B, D) for 2 or 24 hours. LC3 production was analyzed by immunoblotting followed by enhanced chemiluminescence detection, and representative blots are shown (A, B). The intensity of chemiluminescent spots was semiquantitatively estimated by ImageQuant LAS4000, and expressed as the ratio between the intensity of the spot of interest and the intensity of $\beta$-actin bands for cell lysates (C, D). Data are mean \pm standard error of three separate experiments performed in triplicate. Results were compared by Student's $t$-test. $* * P<0.0$ I; 0 dose of MSNPs indicates untreated cells.

Abbreviations: MSNPs, mesoporous silica nanoparticles; HUVECs, human umbilical vein endothelial cells. 
on ECs. MSNPs on cell surfaces were removed by a gentle treatment with trypsin (see "Materials and methods" section for details). The results showed that cellular uptake of NP was size-dependent, with $250 \mathrm{~nm}$ MSNPs strongly internalized by HUVECs $(21 \% \pm 2 \%$ of cellular uptake) compared to the smaller ones $(0.2 \% \pm 0.03 \%$ of cellular uptake).

\section{Evaluation of neuronal electrophysiology after NP exposure}

To study the effect of MSNPs on the neuronal network, reverberating spontaneous burst activity was analyzed. Figure 6 shows the effect of $10 \mu \mathrm{g} / \mathrm{mL} 30 \mathrm{~nm}$ MSNPs. To investigate any type of putative delayed effects, NPs were applied after a control period and the total experiment duration was $\sim 24$ hours. The BD, SN, IBI, and SR data of putative inhibitory (black) and excitatory (red) neurons (30 and 98, respectively) were plotted as a time course, and the arrows indicated the moment of NP application; each point represented a time segment of 30 minutes of mean data. After 2.5 hours in the control sample, we observed that BD and SN remained constant. Only after $\sim 10$ hours did we notice a slow moderate increase to a plateau during the following 7 hours. On the contrary, the time between bursts measured by the IBI plot decreased from $\sim 20$ seconds to $\sim 10$ seconds, as shown in the IBI plot.

As the SR incorporates both the BD and IBI information, we plotted SR as a network-excitability parameter to analyze the global effect of NPs better. The time course of the firing property was similar in both neuron types, revealing an immediate and constant increase in SR. In Figure 7A, we show the average of three similar experiments where we normalized (in control) the SR time courses of excitatory and inhibitory clusters. Although the results showed an increase in excitability following MSNP treatment, no significant differences were detected between different time points. We also tested $10 \mu \mathrm{g} / \mathrm{mL}$ of $250 \mathrm{~nm}$ MSNPs, and no significant variation was observed (Figure 7B) in the network's excitability parameter SR during any of the experiments (BD, SN, and IBI results not shown). Though not statistically significant, it seems that the presence of the $30 \mathrm{~nm}$ MSNPs perturbed network activity with an effect characterized by a long delay. Moreover, a small but transient jump was observed at the moment of MSNP application.

\section{Analysis of MSNP protein coronas by SDS-PAGE}

The composition of protein coronas formed on the MSNP surfaces after incubation in culture medium was analyzed by SDS-PAGE. A representative gel of the MSNP protein coronas is shown in Figure 8. The results showed that the composition of protein coronas changed both qualitatively and quantitatively, depending on the percentage of serum in the culture medium. Moreover, the composition of coronas was also determined by MSNP size.
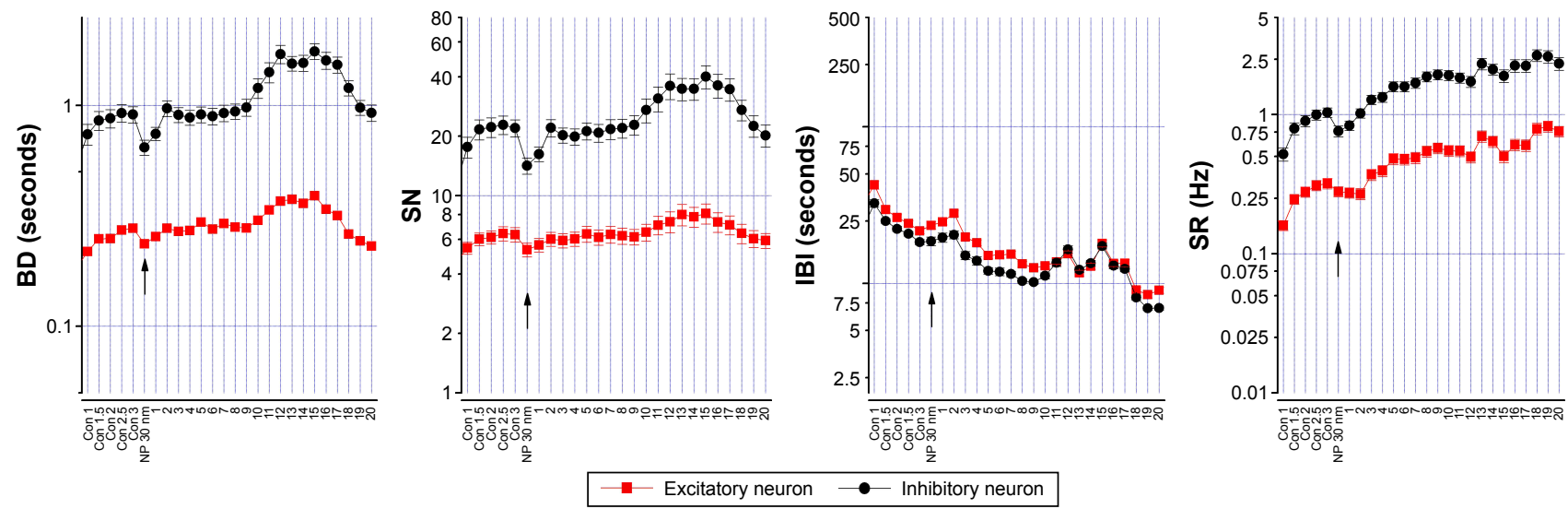

Figure 6 Effect of $30 \mathrm{~nm}$ MSNPs on neuronal activity by MEA technology.

Notes: Firing properties plotted in a time course are BD, SN, IBI, and SR; each point represents an averaged segment time of 30 minutes, and in red and black are the excitatory $(n=97)$ and inhibitory $(n=30)$ clusters, respectively; for each neuron, data were normalized (from minimum to maximum). In controls, averaged data of BD, SN,

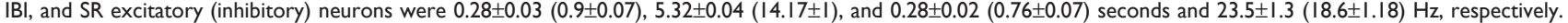
The parameters BD and SN were stationary for almost I0 hours after MSNP addition, then increased transiently. After 12 hours, averaged BD data were $0.37 \pm 0.06$ (I.7 \pm 0.16 ) seconds. Conversely, IBI decreased constantly: at 12 and 20 hours they were $15.45 \pm 0.66$ (I6.47 \pm 0.87$)$ and $9.04 \pm 0.4$ (6.96 \pm 0.21$)$ seconds, respectively. The parameter describing the network as a whole was best represented by SR: its averaged values after I2- and 20 -hour treatment were $0.49 \pm 0.04(\mathrm{I} .72 \pm 0.16)$ and $0.76 \pm 0.06(2.33 \pm 0.24) \mathrm{Hz}$, respectively. Data obtained from an exemplary experiment.

Abbreviations: MSNPs, mesoporous silica nanoparticles; MEA, multielectrode array; BD, burst duration; SN, spike number; IBI, interburst interval; SR, spike rate. 

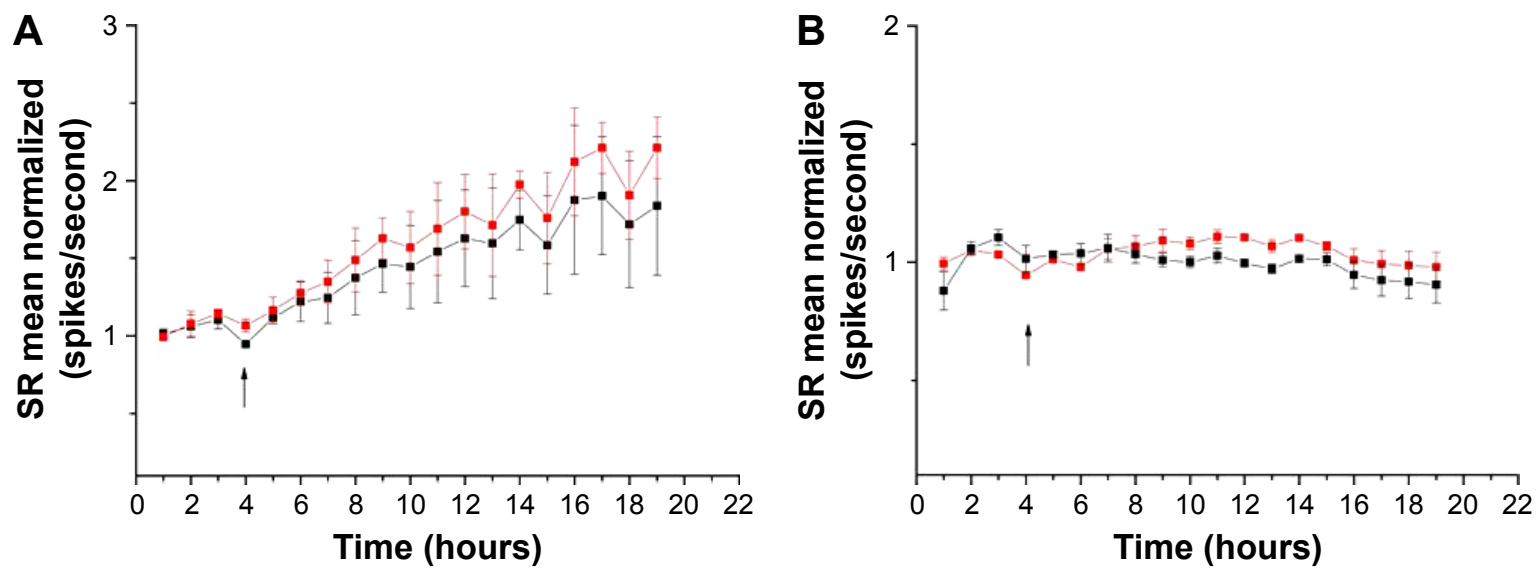

- Excitatory neurons $\quad-$ - Inhibitory neurons $(n=3)$

Figure 7 Normalized averaged SR for experiments with MSNPs of different sizes.

Notes: Each point represents a segment time of 30 minutes, for which averaged data were normalized to mean control value; the arrow indicates MSNP administration. (A) MSNPs of $30 \mathrm{~nm}$ increased mean value of SR versus control: in control and at the end of treatment, the averaged data normalized for excitatory (inhibitory) neurons were I.I $140.03(\mathrm{I} . \mathrm{I} \pm 0.06)$ and $2.2 \mathrm{I} \pm 0.2(\mathrm{I} .8 \pm 0.44) \mathrm{Hz}$, respectively; no significant difference was detected between different time points $(P>0.05)$. (B) MSNPs of $250 \mathrm{~nm}$ did not affect the neuronal network. Values presented as mean \pm standard error of mean obtained from three replicates $(n=3)$.

Abbreviations: MSNPs, mesoporous silica nanoparticles; SR, spike rate.

\section{Discussion}

MSNPs have gained significant attention as promising biomolecule-delivery vehicles. MSNPs are able to enter the human body and reach different organs, such as the brain, liver, lungs, and testes. Therefore, detailed studies regarding their potential toxicity are imperative before MSNPs can be deemed suitable for clinical applications. Although they are considered to exert low toxicity both in vivo and in vitro, the mechanisms involved in the cellular responses activated by MSNPs are not yet clear, particularly considering their
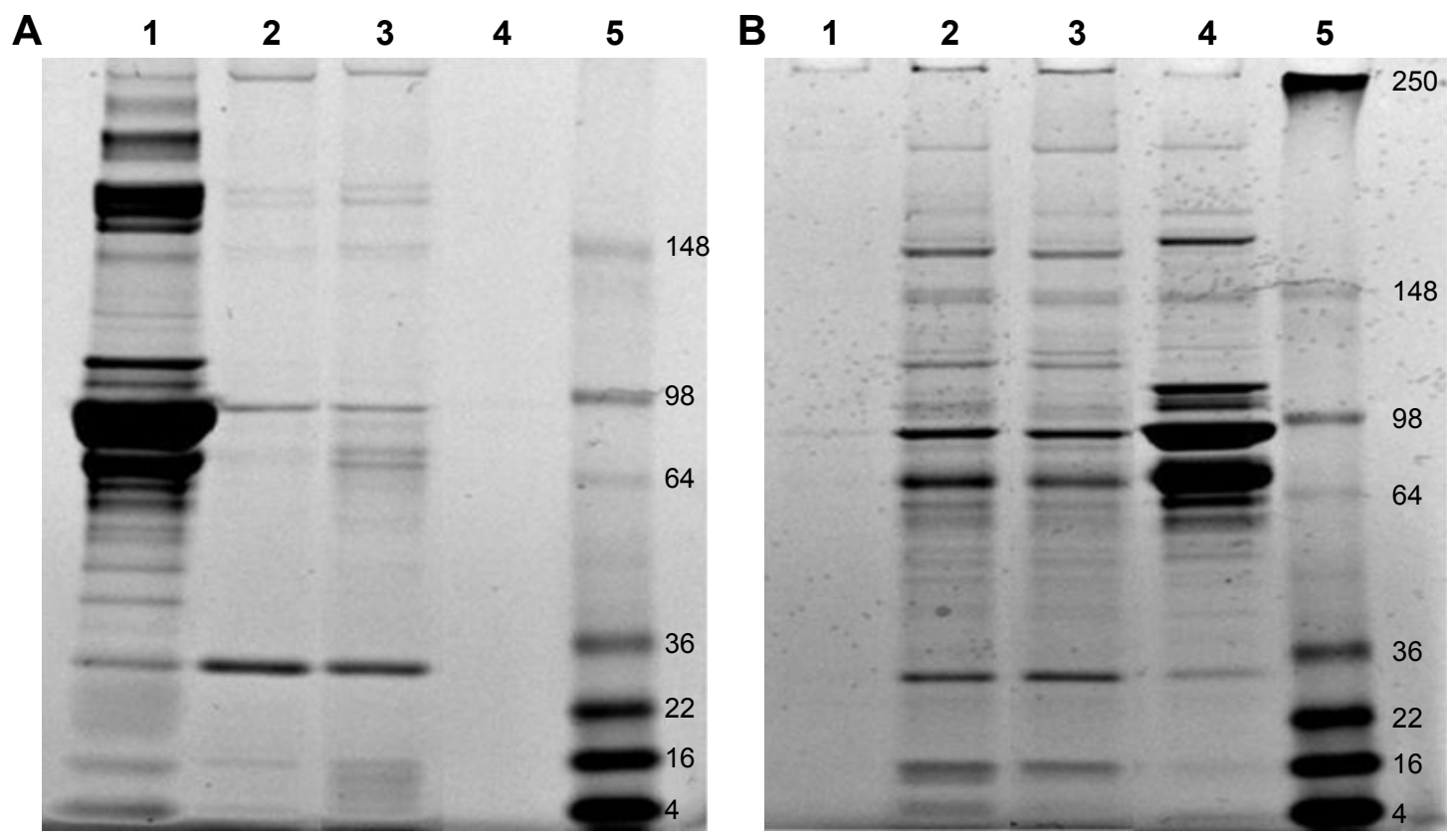

Figure 8 Analysis of MSNP protein coronas by SDS-PAGE.

Notes: MSNPs of different sizes were incubated with cell-culture medium with $5 \%$ or $10 \%$ serum at $37^{\circ} \mathrm{C}$ for 24 hours. After centrifugation to remove unbound serum proteins, pellets were washed three times and then resuspended in $30 \mu \mathrm{L}$ water and analyzed by SDS-PAGE on a I2\% bis-Tris-glycine gel (Thermo Fisher Scientific), followed by EZ blue staining. Representative gels are shown. (A) Protein coronas of MSNPs after incubation in cell-culture medium with $5 \%$ serum. Lane I, aliquot of medium; lane 2 , protein coronas of $30 \mathrm{~nm}$ MSNPs; lane 3, protein coronas of $250 \mathrm{~nm}$ MSNPs; lane 4, medium alone submitted to centrifugation as negative control; lane 5, molecular weight marker. (B) Protein coronas of MSNPs after incubation in cell-culture medium with $10 \%$ serum. Lane I, medium alone submitted to centrifugation as negative control; lane 2, protein coronas of $30 \mathrm{~nm}$ MSNPs; lane 3, protein coronas of $250 \mathrm{~nm}$ MSNPs; lane 4, an aliquot of medium; lane 5, molecular weight marker.

Abbreviations: MSNP, mesoporous silica nanoparticle; SDS-PAGE, sodium dodecyl sulfate polyacrylamide-gel electrophoresis. 
interaction with the brain, the most delicate tissue in the human body. ${ }^{29,30}$ Studies in rodents have shown that MSNPs $(<500 \mathrm{~nm}$ in size $)$ are able to cross the blood--brain barrier ${ }^{31}$ from the periphery, even in the absence of specific surface functionalization for brain targeting. We used an in vitro multiparametric approach to investigate relationships among the size, dose, and exposure time of MSNPs and cellular responses, trying to elucidate the mechanisms of NP-cell interaction. The results showed that at short exposure times ( 2 hours incubation), the toxic effect exerted by $30 \mathrm{~nm}$ MSNPs on ECs was higher compared to that induced by $250 \mathrm{~nm}$ MSNPs. On the contrary, after 24 hours of exposure, $250 \mathrm{~nm}$ MSNPs exerted higher toxicity on ECs in terms of mitochondrial activity and membrane integrity than smaller ones at the same dose. Although the size-dependent toxicity of MSNPs is still controversial, our results are in agreement with those already reported, where particles in the $20 \mathrm{~nm}$ range were more toxic than MSNPs $>100 \mathrm{~nm}$ in diameter after an incubation time of $>24$ hours. $^{32}$ Few data are available about the relationship between time of exposure and toxicity for MSNPs. However, the difference in size may affect the rate of entry of MSNPs into cells, potentially affecting cytotoxicity.

Analyzing biochemical pathways activated by cells in response to MSNP exposure, we found that $250 \mathrm{~nm}$ MSNPs induced more cell autophagy than $30 \mathrm{~nm}$ MSNPs, probably consequent to important cellular NP uptake. These results are in agreement with those reported where cellular uptake and induction of autophagy via the PI3K-Akt-mTOR signaling pathway occurred after HUVEC treatment with nano- $\mathrm{SiO}_{2}$ for 24 hours. ${ }^{11,12}$ ECs do not express typical apoptosis markers, but we can speculate that cells try to activate cell-survival mechanisms, allowing the survival of HUVECs, as suggested for different types of cells after $\mathrm{SiO}_{2}$ exposure. ${ }^{33}$

Interestingly, our results have revealed that autophagy of mitochondria (mitophagy) can be induced by MSNPs as a cellular response for recycling the damaged organelles through molecular mediation associated with change in mitochondrial enzyme activity. ${ }^{34}$ Although there was low uptake of $30 \mathrm{~nm}$ MSNPs, NO production increased, suggesting that NPs could affect endothelial functionality from outside the cells.

The overall results support the idea that size-dependent cellular uptake of MSNPs is a key factor in inducing the cytotoxicity response. Exposure time is crucial in determining the biological cellular response to MSNPs, because it affects cellular uptake. The influence of NP size on their cellular uptake has been widely studied, in particular for gold NPs, but this is an issue that should be investigated further. No toxicity was found after incubation of MSNPs with SKNSH cells as a cellular model of neurons. The MSNP doses tested were lower than those used with ECs, because the quantity of MSNPs that are able to reach the brain after peripheral administration is far below the doses tested here. ${ }^{31}$

To the best of our knowledge, we have shown for the first time that the presence of $30 \mathrm{~nm}$ MSNPs perturbed neuronal network activity, with an effect characterized by a long delay. Moreover, a small but transient jump was observed at the moment of NP application, which could be explained by a mechanical interaction between NPs and cells. It is possible that the delayed SR growth that occurred after 10 hours could be correlated with NP neuronal internalization, supported by the observation that no effect was observed with the $250 \mathrm{~nm}$ MSNPs. It seems reasonable to predict that internalization is easier for smaller-diameter NPs in neuronal cells. Since the effect of $30 \mathrm{~nm}$ MSNPs was highly variable and the neuronal networks were heterogeneous cultures, we cannot exclude the possibility that internalization is easier for specific cellular subtypes. The cellular responses to MSNPs vary between cell lines and depend on the physicochemical features of NPs. The reason for the variability in the biological responses of different cell lines is a very complex issue. ${ }^{35}$

Finally, since it is known that the protein corona can affect NP behavior, including toxicity profile, we analyzed protein coronas of MSNPs after incubation in culture medium with serum. The results showed that the protein-corona composition changed with varying MSNP size. Moreover, the protein-corona electrophoresis profile of MSNPs was different after incubation with culture medium containing different amounts of serum. This suggests that both the size of the NPs and the experimental conditions defined the composition of protein coronas, which in turn could affect the toxicity profile and uptake of NPs.

In fact, we supposed that the different autophagic response activation observed at the higher concentration of MSNP of $30 \mathrm{~nm}$ size compared to larger ones may depend on a different protein corona, which could in turn affect cellular uptake. ${ }^{36}$ This would also explain the increased vitality observed in HUVECs treated with MSNPs of $30 \mathrm{~nm}$ size. With in vitro experiments especially, it would be appropriate to consider the growth conditions of different cellular models. This issue deserves further investigation.

Taken together, these results suggest that $30 \mathrm{~nm}$ MSNPs at doses $<0.25 \mathrm{mg} / \mathrm{mL}$ could be utilized in vivo for biomedical purposes. It is noteworthy that the results derived from in vitro nanotoxicology studies are affected by the aggregation state of particles in culture media, the state in which the NPs are presented to the cells. 


\section{Conclusion}

In conclusion, the results indicate size-dependent cell toxicity exerted by MSNP-induced cell autophagy (in particular, mitophagy) probably consequent to an important MSNP cellular uptake. Increasing the size of particles led to decreased MSNP uptake and increased NO production, suggesting that MSNPs can affect the endothelial functionality from outside the cells. The interaction and internalization of MSNPs by the cells could be influenced by the protein-corona composition of particles, which is affected by NP size and experimental conditions (serum composition of culture media). Moreover, the cellular response to MSNPs was strongly dependent on the cell line used, with doses of MSNPs up to $0.25 \mathrm{mg} / \mathrm{mL}$ perturbing the network activity by increasing excitability, as detected by MEA technology, without affecting neuronal cell viability. This suggests that the potential adverse effects resulting in cell exposure to NPs could occur at different levels of risk.

This study provides in vitro evidence that the use of MSNPs for biomedical purposes might be considered low-risk if they are present at doses $<0.25 \mathrm{mg} / \mathrm{mL}$ with a diameter $<30 \mathrm{~nm}$. The study of the mechanisms activated by the interaction between MSNP and body cells, neurons included, and careful dose-dependent toxicity testing are imperative for the rational design of NPs and treatment schedules before using MSNPs in patients.

\section{Acknowledgment}

This work was supported by a grant from the Italian Fondazione Banca del Monte di Lombardia to FR (CUP H58C13000130003).

\section{Author contributions}

All authors made substantial contributions to conception and design, acquisition of data, or analysis and interpretation of data; took part in drafting the article or revising it critically for important intellectual content; gave final approval of the version to be published; and agree to be accountable for all aspects of the work.

\section{Disclosure}

The authors report no conflicts of interest in this work.

\section{References}

1. Halas NJ. Nanoscience under glass: the versatile chemistry of silica nanostructures. ACS Nano. 2008;2:179-183.

2. Parveen S, Misra R, Sahoo SK. Nanoparticles: a boon to drug delivery, therapeutics, diagnostics and imaging. Nanomedicine. 2012;8:147-166.

3. Bitar A, Ahmad NM, Fessi H, Elaissari A. Silica-based nanoparticles for biomedical applications. Drug Discov Today. 2012;17:1147-1154.
4. Wu J, Wang C, Sun J, Xue Y. Neurotoxicity of silica nanoparticles: brain localization and dopaminergic neurons damage pathways. ACS Nano. 2011;5:4476-4489.

5. Elder A, Gelein R, Silva V, et al. Translocation of inhaled ultrafine manganese oxide particles to the central nervous system. Environ Health Perspect. 2006;114:1172-1178.

6. Napierska D, Thomassen LC, Rabolli V, et al. Size-dependent cytotoxicity of monodisperse silica nanoparticles in human endothelial cells. Small. 2009;5:846-853.

7. Vallhov H, Gabrielsson S, Strømme M, Scheynius A, Garcia-Bennett AE. Mesoporous silica particles induce size dependent effects on human dendritic cells. Nano Lett. 2007;7:3576-3582.

8. He Q, Zhang Z, Gao F, Li Y, Shi J. In vivo biodistribution and urinary excretion of mesoporous silica nanoparticles: effects of particle size and PEGylation. Small. 2011;7:271-280.

9. Duan JC, Yu YB, Li Y, et al. Toxic effect of silica nanoparticles on endothelial cells through DNA damage response via Chk1-dependent G2/M checkpoint. PLoS One. 2013;8:e62087.

10. Duan JC, Yu YB, Li Y, Yu Y, Sun ZW. Cardiovascular toxicity evaluation of silica nanoparticles in endothelial cells and zebrafish model. Biomaterials. 2013;34:5853-5862.

11. Duan JC, Yu YB, Yu Y, et al. Silica nanoparticles enhance autophagic activity, disturb endothelial cell homeostasis and impair angiogenesis. Part Fibre Toxicol. 2014;11:50-58.

12. Duan JC, Yu YB, Yu Y, et al. Silica nanoparticles induce autophagy and endothelial dysfunction via the PI3K/Akt/mTOR signaling pathway. Int J Nanomedicine. 2014;9:5131-5141.

13. Ariano P, Zamburlin P, Gilardino A, et al. Interaction of spherical silica nanoparticles with neuronal cells: size-dependent toxicity and perturbation of calcium homeostasis. Small. 2011;7:766-774.

14. Biedler JL, Helson L, Spengler BA. Morphology and growth, tumorigenicity, and cytogenetics of human neuroblastoma cells in continuous culture. Cancer Res. 1973;33:2643-2652.

15. Parodi A, Haddix SG, Taghipour N, et al. Bromelain surface modification increases the diffusion of silica nanoparticles in the tumor extracellular matrix. ACS Nano. 2014;8:9874-9883.

16. Orlando A, Re F, Sesana S, et al. Effect of nanoparticles binding $\beta$-amyloid peptide on nitric oxide production by cultured endothelial cells and macrophages. Int J Nanomedicine. 2013;8:1335-1347.

17. Re F, Cambianica I, Sesana S, et al. Functionalization with ApoE-derived peptides enhances the interaction with brain capillary endothelial cells of nanoliposomes binding amyloid-beta peptide. J Biotechnol. 2010;156: 341-346.

18. De Kimpe L, Bennis A, Zwart R, van Haastert ES, Hoozemans JJ, Scheper W. Disturbed $\mathrm{Ca}^{2+}$ homeostasis increases glutaminyl cyclase expression; connecting two early pathogenic events in Alzheimer's disease in vitro. PLoS One. 2012;7:e44674.

19. Bana L, Minniti S, Salvati E, et al. Liposomes bi-functionalized with phosphatidic acid and an ApoE-derived peptide affect $\mathrm{A} \beta$ aggregation features and cross the blood-brain-barrier: implications for therapy of Alzheimer disease. Nanomedicine. 2014;10:1583-1590.

20. Hevel JM, Marletta MA. Nitric-oxide synthase assays. Methods Enzymol. 1994;233:250-258.

21. Shi M, Cheng L, Zhang Z, Liu Z, Mao X. Ferroferric oxide nanoparticles induce prosurvival autophagy in human blood cells by modulating the beclin 1/Bcl-2/VPS34 complex. Int J Nanomedicine. 2014;10: 207-216.

22. Gullo F, Maffezzoli A, Dossi E, Wanke E. Short latency cross-and autocorrelation identify clusters of interacting neurons recorded from multi-electrode arrays. J Neurosci Methods. 2009;181:186-198.

23. Wagenaar DA, Pine J, Potter SM. An extremely rich repertoire of bursting patterns during the development of cortical cultures. $B M C$ Neurosci. 2006;7:11.

24. Gullo F, Mazzetti S, Maffezzoli A, et al. Orchestration of "presto" and "largo" synchrony in up-down activity of cortical networks. Front Neural Circuits. 2010;4:11. 
25. Becchetti A, Gullo F, Bruno G, Dossi E, Wanke E. Exact distinction of excitatory and inhibitory neurons in neural networks: a study with GFP-GAD67 neurons optically and electrophysiologically recognized on multielectrode arrays. Front Neural Circuits. 2012;6:63.

26. Duda OR, Hart PE, Stork DG. Pattern Classification. New York: Wiley; 2000.

27. Ham MI, Bettencourt LM, McDaniel FD, Gross GW. Spontaneous coordinated activity in cultured networks: analysis of multiple ignition sites, primary circuits and phase delay distribution. J Comput Neurosci. 2008;24:346-357.

28. Baddeley R, Abbot LF, Booth MC, et al. Responses of neurons in primary and inferior temporal visual cortices to natural scenes. Proc Biol Sci. 1997;264:1775-1783.

29. Rosenholm JM, Sahlgren C, Lindén M. Multifunctional mesoporous silica nanoparticles for combined therapeutic, diagnostic and targeted action in cancer treatment. Curr Drug Targets. 2011;2:1166-1186.

30. Montalti M, Prodi L, Rampazzo E, Zaccheroni N. Dye-doped silica nanoparticles as luminescent organized systems for nanomedicine. Chem Soc Rev. 2014;43:4243-4268.
31. Simkó M, Mattsson MO. Risks from accidental exposures to engineered nanoparticles and neurological health effects: a critical review. Part Fibre Toxicol. 2010;7:42.

32. Kim IY, Joachim E, Choi H, Kim K. Toxicity of silica nanoparticles depends on size, dose, and cell type. Nanomedicine. 2015;11: 1407-1416.

33. Nowak JS, Mehn D, Nativo P, et al. Silica nanoparticle uptake induces survival mechanism in A549 cells by the activation of autophagy but not apoptosis. Toxicol Lett. 2014;224:84-92.

34. Zhang Z, Zhou L, Zhou Y, et al. Mitophagy induced by nanoparticlepeptide conjugates enabling an alternative intracellular trafficking route. Biomaterials. 2015;65:56-65.

35. Zhang X, Shen W, Gurunathan S. Silver nanoparticle-mediated cellular responses in various cell lines: an in vitro model. Int J Mol Sci. 2016;17: $1603-1629$

36. Li J, Mao H, Kawazoe N, Chen G. Insight into the interactions between nanoparticles and cells. Biomater Sci. 2017;5:173-189.
International Journal of Nanomedicine

\section{Publish your work in this journal}

The International Journal of Nanomedicine is an international, peerreviewed journal focusing on the application of nanotechnology in diagnostics, therapeutics, and drug delivery systems throughout the biomedical field. This journal is indexed on PubMed Central, MedLine, CAS, SciSearch $®$, Current Contents $\AA /$ Clinical Medicine,

\section{Dovepress}

Journal Citation Reports/Science Edition, EMBase, Scopus and the Elsevier Bibliographic databases. The manuscript management system is completely online and includes a very quick and fair peer-review system, which is all easy to use. Visit http://www.dovepress.com/ testimonials.php to read real quotes from published authors. 